\title{
PROINFÂNCIA E ESCOLAS DE EDUCAÇÃO INFANTIL: UM ESTUDO SOBRE IMPLANTAÇÃO EM ESTADO DA REGIÃO NORTE
}

\author{
"PROINFANCIA"Y LA EDUCACIÓN INFANTIL ESCUELAS: UN \\ ESTUDIO SOBRE LA INSTALACIÓN EN EL ESTADO DE LA REGIÓN NORTE
}

\author{
“PROINFANCIA" AND CHILDREN EDUCATION SCHOOLS: A STUDY ON \\ IMPLANTATION IN NORTHERN REGION STATE
}

\author{
Juracy Machado PACÍFICO ${ }^{1}$ \\ Sirley Leite FREITAS ${ }^{2}$ \\ Natasha Souza MATOS ${ }^{3}$
}

\begin{abstract}
RESUMO: Este artigo apresenta os resultados dos estudos realizados no período de março a julho/2015, que teve como objetivo analisar o atendimento à creche pela via da implantação do Programa Proinfância em Rondônia. O Proinfância, criado pelo governo federal e instituído pela resolução de $\mathrm{n}^{\circ} 6$, de 24 de abril de 2007, tem como objetivo prestar assistência técnica e financeira para municípios e o Distrito Federal, investindo na construção de creches e equipando-as. O estudo foi realizado, utilizando-se da pesquisa documental em fontes como: sites do FNDE, no Portal de Periódicos da Capes e na Plataforma Scielo e dados da SEMED/PVH-RO. Os estudos realizados e os documentos analisados apontam para o fato de que as crianças necessitam de espaços bem planejados e equipados para que possam desenvolver adequadamente todas as suas potencialidades. Os resultados evidenciam que, dos 52 municípios de Rondônia, somente oito fizeram adesão ao Programa Proinfância e que, mesmo assim, não há como se afirmar que até o ano de 2015 esse programa tenha representado algum impacto no número de matrículas. Conclui-se que será necessário continuar a investigação de forma mais específica para responder a diversas dúvidas que surgiram a partir do contexto atual.
\end{abstract}

PALAVRAS-CHAVE: Educação Infantil. Infraestrutura. Proinfância.

ABSTRACT: This article presents the results of the studies carried out in the period from March5 to July /2015, which had as objective to analyze the attendance to day care through the implementation of the "PROINFANCIA" Program in Rondonia. "PROINFANCIA", created by the federal government and instituted by Resolution No. 6 of April 24, 2007, aims to provide technical and financial assistance to municipalities and the Federal District, investing in the construction of day care centers and equipping them. The study was carried out, using documentary research in sources such as: FNDE sites, Capes Periodical Portal and Scielo Platform, and SEMED / PVH-RO

\footnotetext{
${ }^{1}$ Doutora em Educação pela Universidade Estadual de São Paulo - UNESP e Professora da Universidade Federal de Rondônia - UNIR - Campus Porto Velho - RO - juracypacifico@ unir.br.

${ }^{2}$ Mestra em Educação pela Universidade Federal de Rondônia - UNIR e Professora do Instituto Federal de Educação, Ciências e Tecnologia de Rondônia - IFRO - Campus Cacoal -RO sirleitefreitas@gmail.com.

${ }^{3}$ Acadêmica do curso de Psicologia da Universidade Federal de Rondônia. Bolsista do Programa Institucional de Bolsa de Iniciação Científica - Pibic/CNPq - natashamatos5@ hotmail.com.
}

RIAEE - Revista Ibero-Americana de Estudos em Educação, v.12 , n.1 , p. 228-242, 2017.

E-ISSN: 1982-5587 
data. The studies carried out and the documents analyzed point to the fact that children need well-planned and equipped spaces so that they can adequately develop their full potential. The results show that, of the 52 municipalities of Rondonia, only eight were enrolled in the "PROINFANCIA" Program, and that, even so, there is no way to assert that by the year 2015 this program has had some impact on the number of enrollments. It is concluded that it will be necessary to continue the research in a more specific way to answer several doubts that have arisen from the current context.

KEYWORDS: Early Childhood Education. Infrastructure. "Proinfancia".

RESUMEN: En este artículo se presentan los resultados de los estudios llevados a cabo desde março5 a julio / 2015, cuyo objetivo era analizar el cuidado de cuidado de niños por medio de la aplicación del Programa de "PROINFANCIA" en Rondonia. El "PROINFANCIA", creado por el gobierno federal y establecido por la Resolución $N^{\circ}$ 6 de 24 de abril de 2007, tiene como objetivo proporcionar asistencia técnica y financiera a los municipios y el Distrito Federal, la inversión en la construcción de guarderías y equiparlos. El estudio se llevó a cabo, utilizando fuentes de investigación documental, tales como: sitios FNDE en el Portal de la Capes y la Plataforma Scielo y datos Semed / PVH-RO. Estudios y documentos revisados punto al hecho de que los niños necesitan espacios bien diseñados y equipados para que puedan desarrollar adecuadamente su potencial. Los resultados muestran que, de los 52 municipios de Rondonia, sólo ocho hizo adherencia al programa de "PROINFANCIA" y que, aún así, no hay manera de afirmar que para el año 2015 este programa ha supuesto un impacto en la inscripción. La conclusión es que se debe continuar investigando más específicamente a responder a varias preguntas que han surgido a partir del contexto actual.

PALAVRAS-CLAVE: Educación Infantil. Infraestructura. "Proinfancia”.

\section{Introdução}

Este artigo compreende os resultados decorrentes dos estudos realizados no período de março a julho/2015, tendo como base o plano de trabalho intitulado "Infraestrutura das escolas de Educação Infantil: um estudo sobre a implantação do Proinfância em Rondônia" que teve como objetivo desenvolver estudos sobre o atendimento à creche e implantação do Programa Proinfância em Rondônia, que vem ocorrendo desde o ano de 2008. Nosso estudo abrangeu o período de 2008 a 2015.

O Proinfância, criado pelo governo federal e instituído pela resolução de $n^{\circ} 6$, de 24 de abril de 2007, tem como princípio a melhoria no campo da infraestrutura 
educacional. Assim, buscamos saber se realmente houve impactos positivos desse programa no Estado de Rondônia, especificamente em Porto Velho, capital do Estado.

Antes que déssemos início à pesquisa, levantamos nas plataformas Scielo e nos Periódicos Capes alguns estudos que nos ajudaram na fundamentação teórica do presente relatório. Nosso interesse esteve voltado para: estudos sobre a infância, importância dos espaços, dos ambientes, dos brinquedos e das brincadeiras para o desenvolvimento da criança na primeira infância.

No decorrer do trabalho, buscamos responder à seguinte questão: Qual a importância dos espaços físicos e materiais para o desenvolvimento infantil? Esse foi nosso propósito definido no plano de trabalho "Infraestrutura das escolas de Educação Infantil: um estudo sobre a implantação do Proinfância em Rondônia”, que apresentaremos nos próximos tópicos.

Utilizamos, como ferramentas para o colhimento de dados, as pesquisas bibliográfica e documental. A primeira foi realizada em periódicos, com levantamento nas plataformas Scielo e Periódicos Capes e teve os seguintes indexadores: infraestrutura e educação infantil, Proinfância e Proinfância em Rondônia. A segunda, em que levantamos os dados sobre o Programa Proinfância voltado à infraestrutura das escolas de educação infantil, em especial as creches no Estado de Rondônia, foi realizada no site do Fundo Nacional de Desenvolvimento da Educação (FNDE) e em site com toda a legislação atual do FNDE, denominado FNDE legis, e por meio de dados fornecidos pela SEMED.

\section{Concepções sobre a infância}

No intuito de entendermos a concepção atual sobre o termo infância, tivemos a necessidade de recorrer à história. Considerando o ser humano ser histórico cujas práxis e modos de pensar mudam com o tempo, encontramos na fala de Aranha (2006, p. 19) a importância do passado para entendermos o presente: “[...] o passado não está morto, porque nele se fundam as raízes do presente".

Desde a época antiga já havia uma preocupação com a educação da criança. Platão, em seus estudos, abordou sobre a infância sadia e a primeira infância como fase essencial para a educação moral, voltando-se mais aos estudos médicos, em 
reconhecimento da importância do fator fisiológico e do caráter para a formação do futuro adulto.

Na cultura grega as crianças da primeira infância, no decurso dos sete primeiros anos de vida, estavam por inteiras a cargo da família, o primeiro grupo social responsável pela socialização de um sujeito e principal mediador dos fatores físicos, psicológicos e culturais de uma criança.

As crianças eram submetidas à autoridade do pai, que em suas decisões poderia até abandoná-las. Na concepção romana, a família também era o centro da educação e dava-se relevância à formação do caráter moral dos sujeitos. A criança só era vista como indivíduo quando alcançava a fase adulta (FURLANETTO, 2008).

A concepção da infância como "inoperante, incapaz por ser a criança um ser que nada pode realizar, daí a necessidade de ser guiada pelo adulto" (FURLANETTO, 2008, p. 2706) perdurou pela Idade Média, com a educação cristã, em que os princípios de educação foram fundamentados na religião, teologia, firmados na fé e realizados nos mosteiros e catedrais. Foi também nesse período que apareceu "o pensamento do pecado herdado", que influenciou na visão da criança, que era vista ao mesmo tempo como um "ser malvado e inferior" e "ingênua e inocente” (FURLANETTO, 2008).

A esse respeito temos os estudos de Ariès (2006, p. 17), que pesquisou sobre a história social da criança e da família. O autor destaca que,

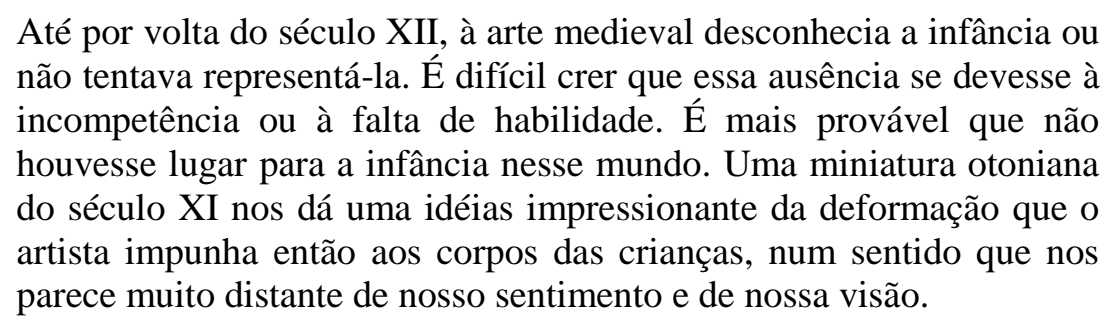

Os estudos de Ariès (2006, p. 18) mostraram que a pintura, em raríssimos casos em que a criança era exposta, apresentava essa com a musculatura do adulto. No século XIII, mesmo já se tendo alterado essa maneira de se retratar a criança, essa matriz ainda permanecia. Destacamos que, "No mundo das fórmulas românticas, e até o fím do século XIII, não existem crianças caracterizadas por uma expressão particular, e sim homem de tamanho reduzido".

Na Idade Média, por volta do século XIII, surgiram algumas características específicas atribuídas à infância, quando antecedeu o então sentimento moderno que no século XVII ganharia força. Por conseguinte, conforme Ariès (2006), surgiram três 
modelos de infância: o primeiro modelo de criança era em forma de querubim, simbolizado sob a aparência de um garoto jovem, o segundo era representado pelo Menino Jesus e a Virgem Maria e o terceiro pela criança nua. Porém, em relação ao Menino Jesus, isso raramente acontecia e isse só ocorreu no final da Idade Média. As crianças não mais eram limitadas ao Menino Jesus e passaram a ser vistas como santas.

Nos períodos Moderno e Contemporâneo, temos a Renascença e com ela o pensamento humanista, momento em que se obtêm uma nova concepção de homem e concomitantemente de criança/infância, predominando, assim, o ser que deve ser adestrado, regulado, ensinando-se as normas para um bom comportamento, de modelo único e universalizado.

Mesmo de forma mecanizada, agora a criança já é capaz de aprender, não sendo mais considerada um ser imóvel, e a Modernidade traz um novo patamar da função social da educação "[...] e a família se torna um núcleo de afetos animada por um "sentimento da infância", que resulta do reconhecimento e da valorização que as crianças passaram a ter no meio em que viviam" (FURLANETTO, 2008, p. 2708).

De acordo com Furlanetto (2008, p. 2708), essa mudança "nos sentimentos e nas relações frente à infância, entre os séculos XVI e XVII, retira a criança do anonimato e inicia um período de conquista para a infância”. Conforme Ariès (1981, p. 194-195), “[...] o extraordinário desenvolvimento da escola no século XVII foi uma consequência dessa preocupação nova dos pais com a educação das crianças".

Nos dias de hoje, temos as Diretrizes Curriculares Nacionais para a Educação Infantil, resolução $n^{\circ} 5$, que, no art. $4^{\circ}$, define a criança como

Sujeito histórico e de direitos que, nas interações, relações e práticas cotidianas que vivencia, constrói sua identidade pessoal e coletiva, brinca, imagina, fantasia, deseja, aprende, observa, experimenta, narra, questiona e constrói sentidos sobre a natureza e a sociedade, produzindo cultura (BRASIL, 2009).

Pacífico (2010, p. 62), considerando esses estudos já desenvolvidos, também fez o destaque de que, "Atualmente, a criança é vista enquanto sujeito de direitos e produtora de conhecimento, incorpora e produz cultura ao mesmo tempo [...]".

Outros autores também fazem essa observação em publicações. Segundo Esteban (2005), nesta nova perspectiva, a criança é vista como um ser em construção que se desenvolve a partir da interação social e deixa de ser vista apenas como um 
adulto em potencial. Assim, a criança vai aprendendo a cada dia como as interações sociais e se habilitando para adquirir mais e mais competências.

No documento Parâmetros Nacionais de Qualidade para a Educação Infantil, produzido em 2006, as crianças já eram consideradas cidadãos de direitos; indivíduos únicos, singulares; seres sociais e históricos; seres competentes, produtores de cultura; indivíduos humanos; parte da natureza animal, vegetal e mineral (BRASIL, 2006). É para o sujeito criança do presente que precisamos de escolas de educação infantil.

Segundo Oliveira (2011, p 139), "desde cedo as crianças se envolvem em interações que podem ser entendidas como trocas de mensagens. Antes de poderem construir uma lógica narrativa, elas constroem uma lógica na ação, por meio de estratégias não verbais". Desta forma, as crianças são capazes de utilizar dessas experiências para poderem compreender um contexto e esclarecer suas construções.

Tendo como base a nova concepção de criança, o profissional para atuar com este público precisa conhecer as teorias sobre desenvolvimento infantil, saber como cada criança constrói, age, reage e modifica sua forma de falar, pensar e sentir. Porém, o educador que trabalha na Educação Infantil também precisa conhecer o uso, a importância e o potencial de aprendizagem existente em cada ação e atividade realizada na instituição infantil (OLIVERIRA, 2011).

O educador deve refletir sobre como utilizar os recursos e materiais disponíveis para desenvolver e ampliar as habilidades e competências necessárias das crianças, para que possam ser inseridas com sucesso na sociedade.

\section{Infraestrutura das escolas de educação infantil: o ambiente, a brincadeira e o brinquedo}

[...] as creches e as pré-escolas surgiram a partir de mudanças econômicas, políticas e sociais que ocorreram na sociedade: pela incorporação das mulheres à força de trabalho assalariado, na organização das famílias, num novo papel da mulher, numa nova relação entre os sexos, para citar apenas as mais evidentes. Mas, também, por razões que se identificam com um conjunto de ideias novas sobre a infância, sobre o papel da criança na sociedade e de como torna-la, através da educação, um indivíduo produtivo e ajustado às exigências desse conjunto social (CRAIDY; SILVA, 2001, p. 2). 
A função das instituições de Educação Infantil vem tomando uma nova concepção nas últimas décadas. Entretanto, Oliveira (2011) afirma que pesquisas realizadas em instituições públicas de Educação Infantil, cerca de dez anos depois da aprovação das Diretrizes Curriculares Nacionais estabelecidas pelo Parecer CNE/CEB n 22/98 e a Resolução CNE/CBE nº 01/99, apontam que em muitas regiões brasileiras ainda se tem uma visão assistencialista do trabalho da Educação Infantil. Por esse motivo, uma discussão e uma nova identidade conceitual e sociopolítica da Educação Infantil se mostrou necessária.

Atendendo a essas e outras demandas foi aprovado pelo Parecer CNE/CEB $n^{\circ}$ 20/2009 e a Resolução CNE/CBE n 05/2009, as novas Diretrizes Curriculares Nacionais para Educação Infantil, que visou enfatizar a proposta pedagógica para as instituições de Educação Infantil, que deve ter por objetivo o desenvolvimento integral da criança de zero a cinco anos de idade em suas dimensões cognitiva, afetiva, motora e social buscando, também, garantir seus direitos em relação a interação com outras crianças, a convivência social, a brincadeira e ao lazer.

Nesta fase na vida as crianças vivem um momento rico em que o convívio com pessoas e com o mundo que as cercam proporciona a elas a atribuição de significados àquilo que as rodeia. Tal ação permite que a criança compartilhe de uma experiência cultural que é própria de seu contexto social, o que se denomina educação. Essa interação não ocorre afastada, fora de um ambiente de cautela, de experiências afetivas e de um contexto material que lhe dá sustentação (BUJES, 2001).

As Diretrizes Curriculares Nacionais para Educação Infantil (Resolução $n^{\circ} 5$ de 17 de dezembro de 2009), art. $5^{\circ}$, destacam:

A Educação Infantil, primeira etapa da Educação Básica, é oferecida em creches e pré-escolas, as quais se caracterizam como espaços institucionais não domésticos que constituem estabelecimentos educacionais públicos ou privados que educam e cuidam de crianças de 0 a 5 anos de idade no período diurno, em jornada integral ou parcial, regulados e supervisionados por órgão competente do sistema de ensino e submetidos a controle social (BRASIL, 2009, p. 1).

Com a necessidade do desenvolvimento integral da criança, dentro do espaço escolar, Kishimoto (2013, p. 6) conota que “Os espaços da Educação Infantil devem ser acolhedores, dinâmicos, envolventes, possibilitar intervenções e auxiliar no desenvolvimento da autonomia da criança". 
Em relação aos bebês, é necessário que sejam pensados a "[...] entrada e acolhimento, sala de atividades, espaço do sono, espaço de banho, espaço de alimentação, solário e jardim sensorial, para que possam usufruir do bem-estar e brincar com tranquilidade" (KISHIMOTO, 2013, p. 6).

Já as crianças de um a três anos, conforme Kishimoto (2013), precisam de um espaço funcional com materiais e brinquedos adequados para poderem se desenvolver tanto nas interações sociais como na questão motora. Desta forma, a sala de atividades deve ter a maior diversidade possível de materiais para possibilitar momentos de descontração, jogos, músicas, histórias, descanso e tranquilidade.

Portanto, as crianças precisam de espaços em que possam desenvolver suas potencialidades ao máximo. Esteban (2005, p. 32) corrobora essa ideia e afirma que:

[...] O cotidiano escolar se insere nesse movimento de descoberta do mundo, de construção da subjetividade e de interação com a vida social. Os caminhos deixam de ser prévia e logicamente traçados, os comportamentos linearmente hierarquizados e atentamente observados, comparados e classificados. Assume-se que, no período 'pré-escolar', a criança está construindo conhecimentos e que esta construção é essencialmente coletiva.

O senso comum acredita que a pré-escola seja apenas um momento de diversão e passatempo, tem a convicção de que as brincadeiras e jogos são apenas ferramentas para entretenimento, entretanto, a função dos mesmos é muito mais ampla. Na fase da primeira infância é quando se tem um maior potencial de aprendizagem, é quando a criança está se descobrindo, descobrindo o mundo e explorando-o.

Segundo Sampaio (2005), a pré-escola não deve ser somente um espaço onde acontece apenas a ocupação do tempo. Deve ser acima de tudo um espaço de uso das diferentes linguagens, dos sentidos e de interação social. O trabalho feito nas préescolas precisa proporcionar às crianças novas descobertas e a construção permanente de saberes e apropriação de novos conhecimentos.

Por exemplo, para que haja o desenvolvimento das habilidades de leitura e escrita, necessárias na alfabetização, é essencial que a criança conheça primeiramente seu corpo interna e externamente, as diferentes formas de objetos, lateralidade, noções de espaço e tempo, entre outros, daí se dá a importância do aprender brincando, fato que afirma a resolução $\mathrm{n}^{0} 5 / 2009$, art. $9^{\circ}$ : “As práticas pedagógicas que compõem a proposta curricular da Educação Infantil devem ter como eixos norteadores as interações e a brincadeira [...]". 
Nesse sentido, Kishimoto (2013) ressalta que é preciso ampliar a qualidade do brincar, mas que para tanto se faz necessário refletir o que é o brincar e como esses acessórios podem contribuir para a diversidade dos temas das brincadeiras, e assim, organizar o espaço, distribuir o tempo e o espaço, preparar as áreas de experiências lúdicas e consequentemente propiciar às crianças momentos constantes de interações sociais, envolvendo as crianças e também os adultos.

É muito importante que o professor dê abertura necessária para que as crianças possam participar ativamente na construção das brincadeiras e que elas possam construir os cenários com outras crianças e com o auxílio do professor.

Conforme a fala de Kishimoto (2013), tanto os brinquedos como as brincadeiras devem ter articulações com o mundo externo para que assim as crianças possam vivenciar seu cotidiano dentro da escola.

[...] o brinquedo possibilita o desenvolvimento total da criança, já que ela se envolve afetivamente no seu convívio social. A brincadeira faz parte do mundo da criança. É nesse momento que ela experimenta, organiza-se, regula-se, constrói normas para si e para o grupo. Desse modo, o brincar é uma das formas de linguagem que a criança usa para entender e interagir consigo mesma e com os outros e o próprio mundo (BUENO, 2010, p. 21).

O ambiente escolar deve ser pensando a fim de contribuir para o melhor desenvolvimento infantil. David e Weinstein (1987) asseveram que os ambientes destinados a crianças devem atender ao menos 5 (cinco) funções, sendo elas: um ambiente que colabore na construção de identidade pessoal; que contribua para o desenvolvimento de habilidades e competências; que promova o crescimento intelectual, motor e social da criança; que seja um ambiente que transmita uma sensação de confiança e segurança; e que oportunize o contato social e momentos de privacidade para as crianças. Desta forma, o ambiente pode contribuir para o pleno desenvolvimento da criança.

Carvalho e Rubiano (2010) também destacam a importância do ambiente na interação entre as crianças e entre as crianças e os adultos. Segundo as autoras o arranjo espacial (que diz respeito ao modo como equipamentos e móveis de um ambiente estão dispostos), pode influenciar no tipo de interação entre as crianças e entre as crianças e adultos. Assim, ambientes com zonas circunscritas contribuem mais para interação afiliativas entre as crianças. Ambientes com ausência de zonas circunscritas dificultam a interação entre as crianças, mesmo com a presença e orientação de um adulto. Já no 
ambiente com a presença de barreiras físicas que dificultem o campo amplo de visão, as crianças tendem a interagir mais com os adultos do que com as crianças.

Desta feita, o espaço, bem como o ambiente em que poderá ser organizado, devem garantir a possibilidade de desenvolvimento de diferentes atividades com as crianças e pelas crianças. Um ambiente alegre, com materiais adequados e com docentes bem formadas para o trabalho pedagógico é sinônimo de educação de qualidade para as crianças que conseguem uma matrícula na escola de educação infantil. Vale ressaltar que a escola de educação infantil ainda não é realidade para todas as crianças.

Quando crianças e profissionais interagem em uma instituição educativa, nem sempre o fazem por sua própria vontade e iniciativa, embora pareça ser natural, nos dias de hoje, que estas interações se processem. [...] Isso significa que os profissionais e as crianças envolvidas nas interação pedagógicas necessitam exercitar, permanentemente, procedimentos que levem à abstração e ao rigor, na difícil tarefa de articulação entre distintos tipos de conhecimentos, promovendo experiências interacionais educativas diversificadas; as manifestações genuínas, típicas do lúdico; a realização de tarefas com parceiros predeterminados ou não pelo adulto; o estudo e a sistematização dos conteúdos abordados no grupo (MACHADO, 2010, p. 50).

Cabe ressaltar que na instituição de educação infantil, numa perspectiva sociointeracionista, é preciso haver um respeito em relação ao papel e importância da criança, reconhecer seus conhecimentos, sua afetividade e como interagem entre si e com os adultos.

\section{Resultados e discussões}

O Programa Nacional de Reestruturação e Aquisição de Equipamentos para a Rede Escolar Pública de Educação Infantil (Proinfância), criado pelo governo federal e instituído pela resolução $\mathrm{n}^{\circ}$ 6, de 24 de abril de 2007, que estabelece as orientações e diretrizes para execução e assistência financeira suplementar ao Proinfância, frisa a melhoria no campo da infraestrutura educacional, tendo como principal objetivo a prestação de assistência técnica e financeira para municípios e o Distrito Federal com o intuito de construir creches e equipá-las, assegurando, assim, o acesso de crianças a creches e à educação infantil da rede pública. De acordo com Flores e Mello (2014, p. 1), "trata-se de uma política pública cujo objetivo é ampliar a oferta de vagas na 
primeira etapa da Educação Básica, a partir do repasse de recursos federais destinados à construção de prédios para o funcionamento de estabelecimentos de Educação Infantil".

As escolas construídas obedecem aos ambientes que o programa tem como imprescindíveis, como: sanitários, fraldários, salas de aula, sala multiuso, recreio coberto, parque, refeitório e outros mais, em que possam ser desenvolvidas atividades recreativas, pedagógicas, esportivas e de alimentação, além dos espaços para o administrativo e de serviço.

O programa não só constrói escolas, mas também distribui recursos para as escolas de educação infantil na reta final de construção, oferecendo-lhes itens padronizados e adequados para o seu andamento. Conforme o site do Portal do FNDE, mais de 2.500 cidades receberam ajuda do FNDE para a aquisição de mobílias e equipamentos, como, por exemplo, geladeiras, fogões, bebedouros, mesas, cadeiras e berços.

Os pré-requisitos para a solicitação dos recursos do Proinfância incluem o cadastramento do projeto, via SIMEC, no módulo Plano de Ações Articuladas (PAR), nos períodos pré-estabelecidos. Para que ocorra o cadastramento das prefeituras, o município deverá ter: disponibilidade de terreno em localização; condições de acesso e características geotécnicas e topográficas adequadas para a implantação das unidades, segundo as exigências dos projetos padronizados, oferecidos pelo FNDE (tipos a, b e c); compromisso com a gestão, funcionamento e manutenção das unidades; déficit comprovado de vagas na educação infantil.

Quadro 1: Municípios contemplados com unidades de educação infantil no âmbito do

PAC 2

Relação dos municípios de Rondônia selecionados para a construção de UNIDADES DE EDUCAÇÃO INFANTIL Programa Pró-Infância no âmbito do PAC 2 - 2010/2011.

\begin{tabular}{|c|c|c|c|c|}
\hline $\mathrm{N}^{\circ}$ & Município & Chamada & Código PAC & Qnt/Uni. \\
\hline 1 & Ariquemes & $1^{\mathrm{a}}$ & Grupo I & 1 \\
\hline 2 & Cacoal & $1^{\mathrm{a}}$ & Grupo I & 1 \\
\hline \multirow{2}{*}{3} & \multirow{2}{*}{ Porto Velho } & $1^{\mathrm{a}}$ & Grupo I & 6 \\
\cline { 3 - 5 } & & $2^{\mathrm{a}}$ & Grupo I & 2 \\
\hline 4 & Rio Crespo & $2^{\mathrm{a}}$ & Grupo III & 1 \\
\hline 5 & Cacaulândia & $3^{\mathrm{a}}$ & Grupo III & 1 \\
\hline 6 & São Felipe d'Oeste & $3^{\mathrm{a}}$ & Grupo III & 1 \\
\hline 7 & Teixeirópolis & $3^{\mathrm{a}}$ & Grupo III & 1 \\
\hline
\end{tabular}

Fonte: Elaboração própria a partir de informações coletadas na SEMED/PVH, 2015. 
Observamos que somente sete municípios aderiram ao Proinfância no período, e que somente Porto Velho solicitou um quantitativo maior de escolas, chegando a um total de oito unidades contratadas. Os demais municípios, um total de seis, solicitaram apenas uma unidade. Observamos também que três municípios: Rio Crespo, Cacaulândia e São Felipe D'Oeste não tinham à época, e ainda não têm em 2015 , nenhuma matrícula na etapa da creche.

Observamos que não são tantas escolas se considerarmos a demanda existente no Estado de Rondônia. O Quadro 2 nos apresenta um resumo das matrículas na etapa da educação infantil - creche, no período de 2008 a 2013, ficando visível o baixo atendimento. Mais abaixo apresentamos os dados de matrícula de todos os municípios separadamente.

São dados reais da ausência de atendimento à creche. Um mínimo, ínfimo, que não pouco representa se consideramos a quantidade de crianças que muito precisam desses espaços de socialização, convivência, desenvolvimento e aprendizagens.

Quadro 2: Rondônia - População de zero a três anos, matrícula e taxa de cobertura $2008 / 2013$

\begin{tabular}{|c|c|c|c|c|c|c|c|c|c|c|}
\hline \multirow{2}{*}{ Ano } & \multicolumn{2}{|c|}{$\begin{array}{c}\text { População } \\
\text { Total de 0 a 3 } \\
\text { anos }\end{array}$} & \multicolumn{2}{c|}{$\begin{array}{c}\text { Matrícula } \\
\text { escolas } \\
\text { públicas }\end{array}$} & \multicolumn{2}{c|}{$\begin{array}{c}\text { Matrícula } \\
\text { escolas } \\
\text { privadas }\end{array}$} & \multicolumn{2}{c|}{$\begin{array}{c}\text { Taxa de } \\
\text { cobertura } \\
\text { rede pública }\end{array}$} & \multicolumn{2}{c|}{$\begin{array}{c}\text { Taxa de cobertura } \\
\text { rede privada }\end{array}$} \\
\cline { 2 - 12 } & Urbano & Rural & Urbano & Rural & Urbano & Rural & $\%$ & $\%$ & $\%$ & $\%$ \\
\hline 2008 & 76.114 & 46.403 & 6.815 & 0 & 2.311 & 0 & 9,0 & 0,0 & 3,0 & 0 \\
\hline 2009 & 76.114 & 46.403 & 7.500 & 0 & 2.621 & 0 & 9,9 & 0,0 & 3,4 & 0 \\
\hline 2010 & 75.572 & 25.802 & 7.971 & 38 & 2.440 & 0 & 10,5 & 0,1 & 3,2 & 0 \\
\hline 2011 & 75.572 & 25.802 & 8.405 & 51 & 2.629 & 0 & 11,1 & 0,2 & 3,5 & 0 \\
\hline 2012 & 75.572 & 25.802 & 9.301 & 61 & 2.991 & 0 & 12,3 & 0,2 & 4,0 & 0 \\
\hline 2013 & 75.572 & 25.802 & 10.399 & 148 & 3.242 & 0 & 13,8 & 0,6 & 4,3 & 0 \\
\hline
\end{tabular}

Fonte: Elaboração própria a partir dos dados do Microdados do censo demográfico IBGE, 2010 e Microdados do Censo Escolar (INEP, 2015).

O déficit de vagas para crianças de zero a três anos é grande no Estado de Rondônia. Em 2013 a rede pública atendia a menos de 14\% do número de crianças com direito a vagas em escolas de educação infantil. Se reunirmos as duas redes, pública e privada, ainda assim não atingimos $20 \%$ das crianças com idade de zero a três anos. Podemos afirmar que esse déficit compreende totalmente as camadas populares, visto que as classes média e alta, querendo escola, terão, mesmo que com atendimento privado. É evidente que os municípios têm recursos para a construção de escolas, mas geralmente não priorizam a educação infantil. 


\section{Considerações finais}

Por meio dos estudos teóricos realizados foi possível compreendermos o enorme papel que as instituições de educação infantil exercem no desenvolvimento psíquico, intelectual e motor das crianças pequenas, pondo em evidência a importância dos investimentos na infraestrutura das escolas e levando em conta esse ser capaz de vivenciar e produzir cultura.

A criança interage com o meio em que vive e esse meio deve oferecer as ferramentas necessárias para o desenvolvimento pleno e integral dela, com o objetivo primordial de formar cidadãos autônomos. É de extrema importância que esses espaços sejam bem planejados, com o mínimo possível de riscos à integridade física e mental das crianças.

No entanto, se os investimentos feitos pelo Proinfância no Estado de Rondônia ajudaram na aquisição, melhoramento e construção de novas unidades de educação infantil, isso ainda será assunto de estudos posteriores, pois, pelos dados documentais levantados, essa afirmação não será possível. Pelos dados inferimos que não houve impacto positivo na ampliação do atendimento, com qualidade, à creche, mas isso ainda requer estudos in loco.

Queremos discutir os usos dos espaços físicos para atender às crianças das creches das escolas construídas com recursos do Proinfância em Rondônia, mas nos deparamos com a quase ausência desses espaços e de crianças matriculadas em turmas de creche. Numa perspectiva de continuidade desta pesquisa, concluímos que não basta haver ambientes ricos em possibilidades de desenvolvimento, mas há o uso, instrução e manuseio correto desses materiais e espaços, que serão competências da equipe pedagógica das escolas. Nesse sentido, a visita às escolas construídas e equipadas com recursos do Proinfância para análise dos materiais disponíveis e da prática pedagógica será nosso próximo passo.

\section{Referências}

ARANHA, M. L. A. História da educação e da pedagogia. São Paulo: Moderna, 2006. 
ARIÈS, P. História social da criança e da família. Trad. Dora Flaksman. 2. ed. Rio de Janeiro: LTC, 1981.

ARIÈS, P. A descoberta da infância. In: ARIÈS, P. História social da criança e da família. Trad. Dora Flaksman. 2. ed. Rio de Janeiro: LTC, 2006. Cap. 2, p. 39-68.

BRASIL. FNDE Legislação. Disponível em:

$<$ https://www.fnde.gov.br/fndelegis/action/ResenhaAction.php?acao=recuperarResenha Modulo\&cod_menu=355\&cod_modulo=9>. Acesso em: 13 abr. 2015.

Ministério da Educação. Secretaria de Educação Básica. Parâmetros

nacionais de qualidade para a educação infantil. Brasília: MEC, 2006.

Ministério da Educação. Secretaria da Educação Básica. Indicadores da

qualidade na educação infantil. Brasília: MEC/SEB, 2009.

BUENO, Elizangela. Jogos e Brincadeiras na Educação Infantil: Ensinando de forma lúdica. UEL: Londrina, 2010.

BUJES, M. I. E. Escola Infantil: Pra que te quero? In: CRAIDY, C. M.; SILVA, G. E. P. (Orgs.). Educação Infantil: Pra que te quero? Porto Alegre: Artmed, 2001. Cap. 1, p. $13-22$.

CARVALHO, Mara I. Campos; RUBIANO, Márcia R. Bonagamba. Organização do espaço em instituições pré-escolares. In: OLIVEIRA, Zilma Moraes Ramos de.

Educação infantil: muitos olhares. 9. ed. São Paulo: Cortez, 2010, p. 116-142.

CRAIDY, C. M.; SILVA, G. E. P. (Orgs.). Educação Infantil: Pra que te quero? Porto Alegre: Artmed, 2001.

DAVID, T. G.; WEINSTEIN, C. S. . The built environment and children's

development. In: WEINSTEIN, C. S.; DAVID, T. G. . Spaces for children: The built environment and child development. New York: Plenum, 1987, p. 3-18.

ESTEBAN, Maria Teresa. Jogos de encaixe: educar ou formatar desde a pré-escola. In: Regina leite Garcia (Org.). Revisitando a Pré-escola. 6. ed. Cortez: São Paulo, 2005.

FLORES, Maria Luiza Rodrigues; MELLO, Débora Teixeira de. Ampliação do acesso à educação infantil via proinfância: análises de uma política pública em colaboração

Rio Grande do Sul: UFRGS, 2012; Santa Maria: UFSM, 2012.

FURLANETTO, B. H. Da infância sem valor à infância de direitos: diferentes construções conceituais de infância ao longo do tempo histórico. In: CONGRSSO NACIONAL DE EDUCAÇÃO, 8., 2008, Curitiba. Anais ... Curitiba: PUCPR, 2008. p. 2704-2717.

INEP-Instituto Nacional de Estudos e Pesquisas Educacionais Anísio Teixeira. Dados finais do censo escolar. Disponível em: <http://portal.inep.gov.br/basica-censo-escolarmatricula>. Acesso em: 14 mar. 2015.

KISHIMOTO, T. M. Introdução. Salto para o Futuro, Rio de Janeiro, ano 23, p. 4-8, 2013. 
MACHADO, Maria Lucia de A. Educação infantil e sociointeracionismo. In: OLIVEIRA, Zilma Moraes Ramos de. Educação infantil: muitos olhares. 9. ed. São Paulo: Cortez, 2010, p. 25-53.

PACÍFICO, J. M. Políticas públicas para a Educação Infantil em Porto Velho/RO (1999/2008). 2010. 358 f. Tese (Doutorado em Educação Escolar) - Faculdade de Ciências e Letras de Araraquara, Universidade Estadual Paulista, Araraquara, 2010.

SAMPAIO, Carmen Sanches. Alfabetização na Pré-escola. In: Regina leite Garcia (Org.). Revisitando a Pré-escola. 6. ed. Cortez: São Paulo, 2005.

\section{Como referenciar este artigo}

PACÍFICO, Juracy Machado.; FREITAS, Sirley Leite.; MATOS, Natasha Souza. Proinfância e escolas de educação infantil: um estudo sobre implantação em estado da Região Norte. Revista Ibero-Americana de Estudos em Educação, Araraquara, v.12, n.1, p. 228-242, 2017. Disponível em: 〈http://dx.doi.org/10.21723/riaee.v12.n1.8235>. E-ISSN: 1982-5587.

Data de submissão: nov/2015

Aprovação final: jan/17 